\title{
DETERMINING THE BASIS FOR A TAXONOMY OF MECHANICAL VENTILATION
}

\author{
by \\ Robert L. Chatburn, RRT-NPS, FAARC \\ Submitted in Partial Fulfillment of the Requirements \\ for the Degree of \\ Master of Health and Human Services
}

YOUNGSTOWN STATE UNIVERSITY

May, 2010

Digitally signed by ETD 


\title{
DETERMINING THE BASIS FOR A TAXONOMY OF MECHANICAL VENTILATION
}

\author{
Robert L. Chatburn, RRT-NPS, FAARC
}

I hereby release this thesis to the public. I understand that this thesis will be made available from the OhioLINK ETD Center and the Maag Library Circulation Desk for public access. I also authorize the University or other individuals to make copies of this thesis as needed for scholarly research.

Signature:

Robert L. Chatburn, Student

Date

Approvals:

Dr. Salvatore A. Sanders, Thesis Advisor

Date

Dr. Louis N. Harris, Committee Member

Date

Teresa A. Volsko, Committee Member

Date

Dr. John M. Hazy, Committee Member

Date

$\overline{\text { Dr. Peter J. Kasvinsky, Dean, School of Graduate Studies and Research } \quad \text { Date }}$ 
(C) 2010

Robert L. Chatburn 


\begin{abstract}
Over the last 30 years, there has been a rapid evolution of the technologic capabilities of mechanical ventilators. These capabilities have motivated the creation of dozens of names to describe modes of ventilation. This proliferation of names has become counterproductive, making education of end users very difficult and potentially compromising the quality of patient care. Therefore, this study was designed as a survey of stakeholders in a taxonomy of mechanical ventilation. The specific hypotheses were that 1) There is sufficient ( $>50 \%$ ) concordance on 10 basic constructs related to mechanical ventilation modes to form the basis for a standardized taxonomy; 2) Concordance with the basic constructs will vary among stakeholders according to their professional training and professional activity; 3) The degree of concordance will vary among the set of constructs. Methods: The study was designed as an Internet based survey. The survey population was composed of physicians, respiratory therapists, nurses, engineers and others involved with mechanical ventilation. Invitations to participate were emailed to 2,994 people internationally. Hypotheses were tested with Chi Square, with $\mathrm{P}<0.05$ considered significant. Results: Of the emails sent, 185 were returned as undeliverable. Survey responses were received from 432 people (15.4 \% response rate). Respondents were $55.3 \%$ respiratory therapists, $35.4 \%$ physicians, 2.5\% nurses, $1.4 \%$ engineers, and $5.3 \%$ other professionals. Overall, there was an $82.4 \%$ concordance with the 10 constructs, significantly greater than the postulated $50 \%$ (P < 0.001). When the data were grouped by profession, respiratory therapists showed the highest degree of concordance (84.3\%) and "other profession" showed the lowest
\end{abstract}


(79.1\%), $\mathrm{P}=0.006$. When the data were grouped by professional activity, there was no significant difference $(\mathrm{P}=0.072)$ in concordance. Concordance differed significantly among the survey questions $(\mathrm{P}<0.001)$ indicating either confusion about question wording or disagreement with the underlying construct. Conclusions: The results of this survey indicate that the respondents were either familiar with or amenable to the previously published literature that the survey constructs represented. Furthermore, the degree of familiarity and concordance with these constructs represents a sufficient basis for attempting to formalize a taxonomy. Further analysis of the pattern of concordance among the constructs will inform future educational and consensus building efforts. 


\section{TABLE OF CONTENTS}

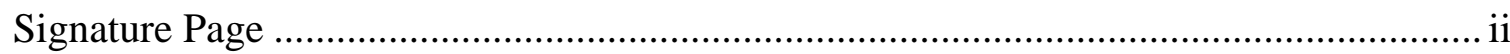

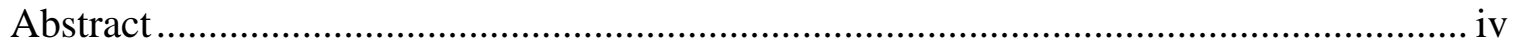

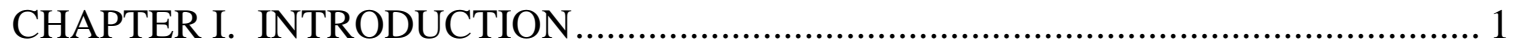

Statement of Research Problem ............................................................................ 2

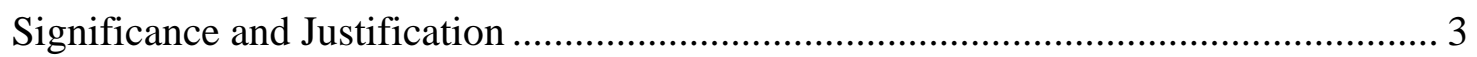

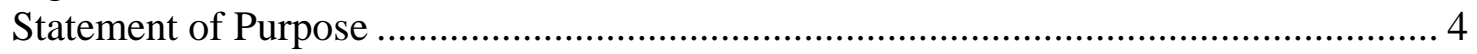

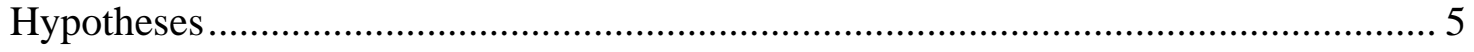

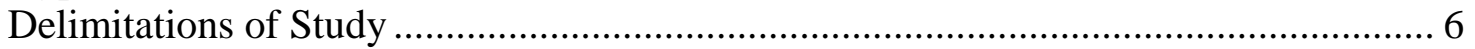

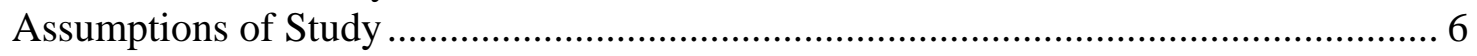

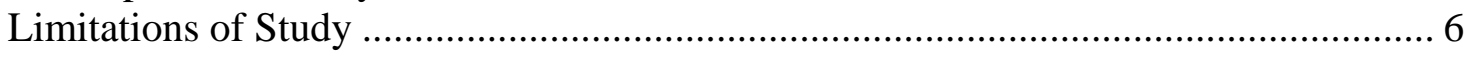

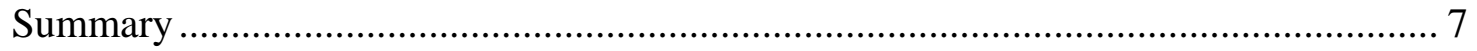

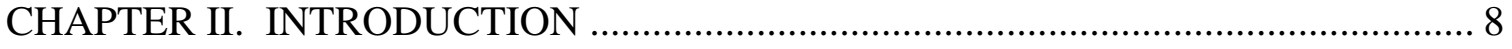

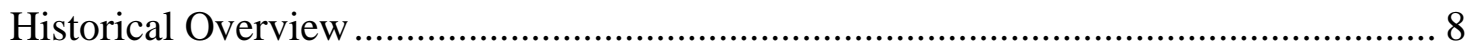

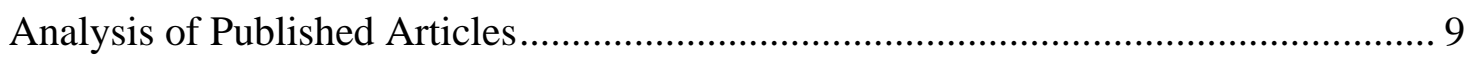

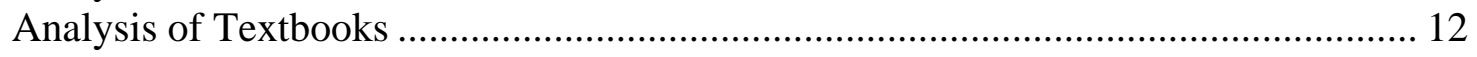

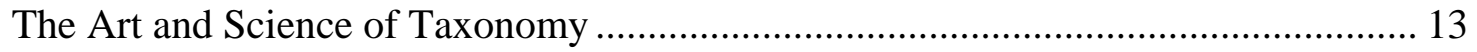

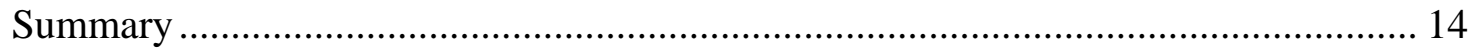

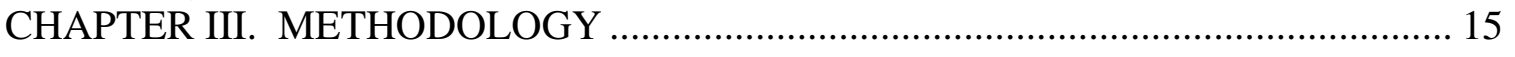

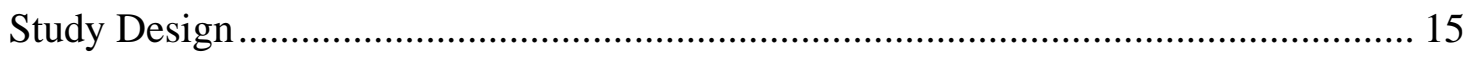

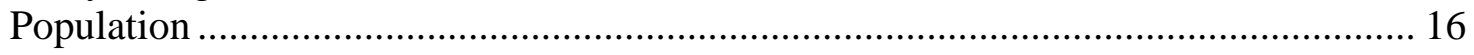

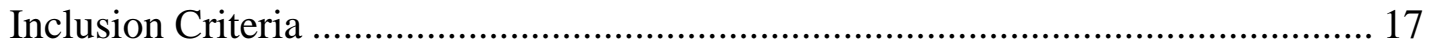

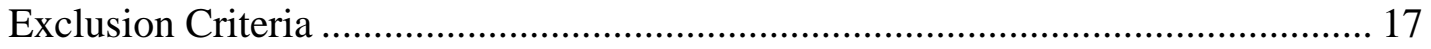

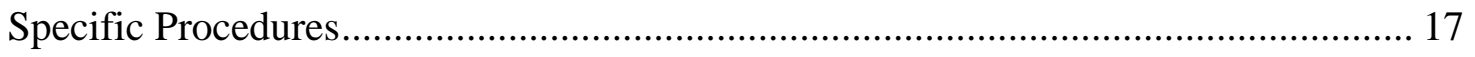

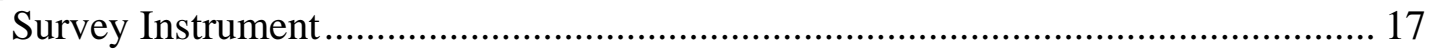

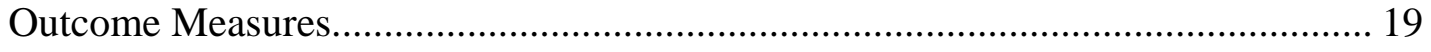

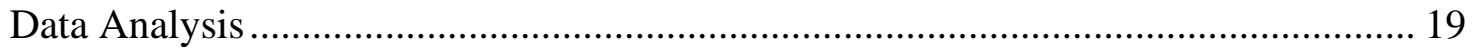

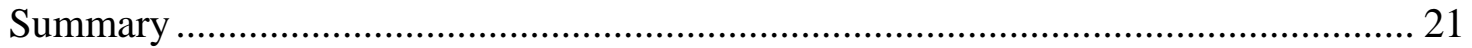

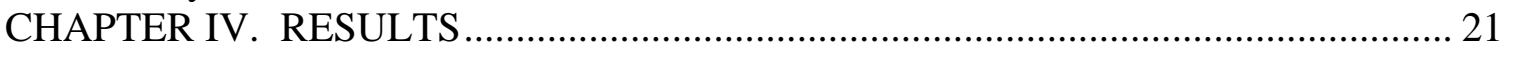

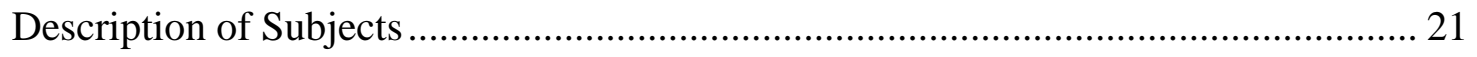

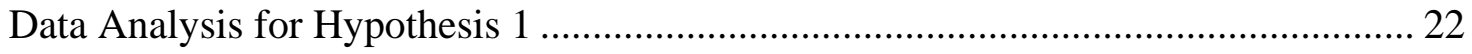

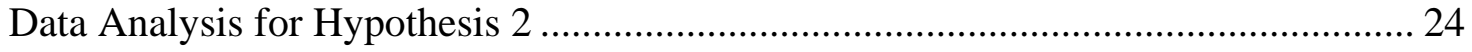

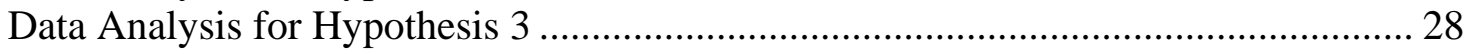

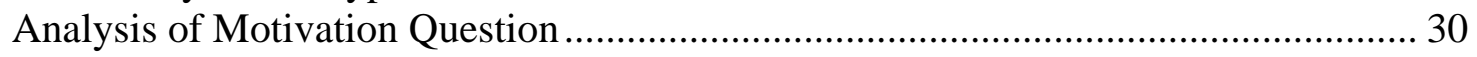

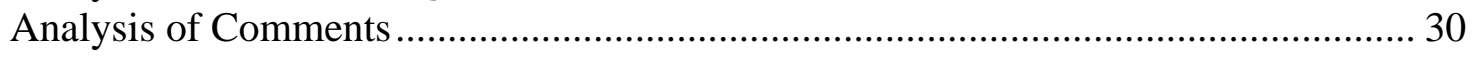

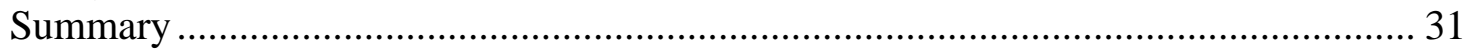

CHAPTER V. SUMMARY, CONCLUSIONS AND RECOMMENDTioNS ............... 33

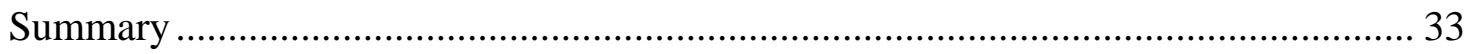

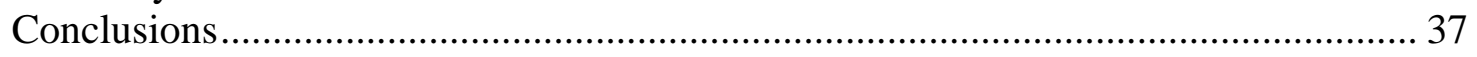

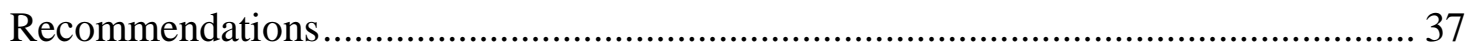

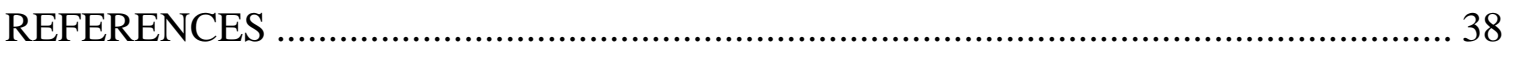

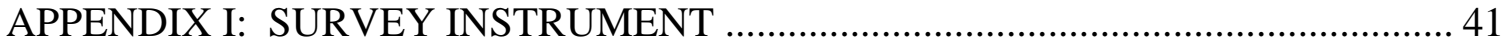

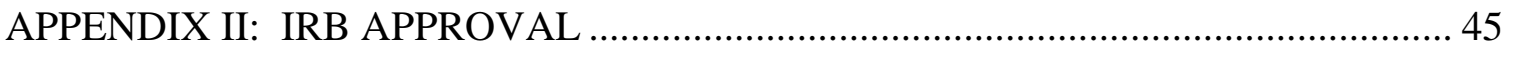




\section{LIST OF TABLES}

Table 1. Qualitative ranking of the degree of agreement based on the kappa statistic..... 20

Table 2. Survey response grouped by professional training. ........................................ 21

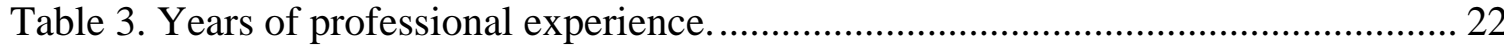

Table 4. Survey response grouped by professional activity. ....................................... 22

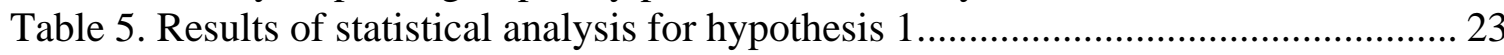

Table 6. Results of statistical analysis for hypothesis 2 related to profession................. 24

Table 7. Results of statistical analysis for hypothesis 2 related to professional activity. . 26

Table 8. Results of statistical analysis for hypothesis 3............................................. 29

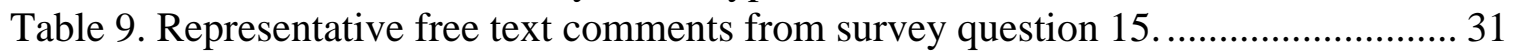

\section{LIST OF FIGURES}

Figure 1. Matrix used to calculate the kappa statistic................................................... 23

Figure 2. Concordance when data were grouped by profession. ................................... 24

Figure 3. Response to survey questions by different professional groups....................... 25

Figure 4. Concordance when data were grouped by professional activity. ..................... 26

Figure 5. Response to survey questions grouped by professional activity...................... 27

Figure 6. Comparison of concordance among survey questions. ................................... 28 


\section{CHAPTER I. INTRODUCTION}

In the profession of respiratory care, the most important skills center on life support. Specifically, these life support skills involve resuscitation from cardiopulmonary arrest and management of mechanical ventilation. In particular, mechanical ventilation is a skill that is not taught to medical students, so physicians learn on the job, primarily from their respiratory therapy colleagues (at least in the United States). Conversely, respiratory therapists have to undergo formal training in mechanical ventilation to obtain credentials and state licensure.

Like many other professions, respiratory care has experienced a remarkable increase in technological complexity in just the last 30 years. Unfortunately, systems of formal education have not evolved rapidly enough to keep pace, particularly in the area of mechanical ventilation. A mechanical ventilator is an automatic machine designed to replace some or all of the work the body must produce to move air into and out of the lungs. ${ }^{1}$ In the most general terms, a "mode of ventilation” is a predetermined pattern of interaction between the ventilator and the patient. Thirty years ago, the average mechanical ventilator offered 2 or 3 mode selections. Today, state-of-the-art mechanical ventilators may have as many as 2 dozen modes, some of which may even employ computerized artificial intelligence. In the course of one human generation, mechanical ventilators have evolved perhaps 5 generations. What has not evolved is a standardized taxonomy sufficient to describe this technological complexity. Despite repeated attempts, no official glossary of mechanical ventilation exists either among health care organizations or manufacturers. On the contrary, manufacturers have exacerbated the 
problem by coining a plethora of names for modes and how they work in an effort to create product differential and increase sales.

As a result of not having a standardized taxonomy, 4 major problems accrue: (1) published studies of mechanical ventilation are hard to compare ${ }^{2}$ and thus appropriate evidence for clinical practice is difficult to assemble and describe; (2) there is little consistency among respiratory therapy educational programs regarding nomenclature and descriptions of how ventilators work; (3) clinicians practicing in institutions with mechanical ventilators supplied by several different manufacturers (a very common situation) do not have the time or educational resources to receive adequate training and experience with all modes on all ventilators, making optimal ventilator management unattainable and; (4) manufacturers can no longer easily communicate with prospective clients regarding the detailed operation of their products in relation to competitive devices, thus limiting the effectiveness of both sales and training, which in turn, exacerbates the other problems.

\section{Statement of Research Problem}

To date, no official consensus has been developed among either manufacturers or professional organizations related to the taxonomy of mechanical ventilation therapy for acutely ill patients, despite many textbooks and published manuscripts on the subject. As a result of these publications, a core set of constructs does exist that could serve as the nucleus of a consensus. However, no data exist to determine if such a consensus might be attainable. 


\section{Significance and Justification}

The first popular textbook dedicated to respiratory care equipment was written in 1977 by Steve McPherson. ${ }^{3}$ Sixty five percent of the pages were devoted to mechanical ventilation, but only 3 “modes” of ventilation were explicitly mentioned: “control”, “assist/control”, and “spontaneous breathing”. Indeed, specific “modes” were never listed in the book's tables of ventilator specifications. Rather, descriptions in this textbook, and labeling on ventilators themselves, seemed to focus more on specific drive mechanisms and settings apart from how settings may be grouped together into identifiable modes of operation. For example, the description of a ventilator might be “...electrically powered, rotary-driven piston, double-circuit, time-cycled, time- and volume-limited controller...”

In, the $7^{\text {th }}$ edition of McPerson's equipment book (2004), about two thirds of the book’s pages are still devoted to mechanical ventilation. ${ }^{4}$ However, 19 pages are devoted exclusively to "modes of ventilation”. Twenty two specific modes are described in these pages. However, in the following pages describing specific ventilators, 93 unique mode names are mentioned. But they are not 93 unique modes. There are many cases of different names for identical modes (e.g., Pressure-Control Ventilation Plus Adaptive Pressure Ventilation on the Hamilton Galileo is the same as Pressure Regulated Volume Control on the Siemens Servo 300) and a few cases of the same name used for very different modes (e.g., “Assist/Control” on the Puritan Bennett 840 is a form of volume control whereas "Assist/Control” on the Bear Cub infant ventilator is a form of pressure control). Ventilator manufacturers and the respiratory medicine academic community have not yet adopted a standardized system for classifying and describing the technology of mechanical ventilation (i.e., “modes of ventilation”). As a result, the risk for confusion 
affects many aspects of the respiratory care professions, from sales and marketing, to education. Lack of understanding has the potential for negative patient care outcomes.

In a recent meeting of a ventilator subcommittee of the International Organization for Standardization (ISO), Beier, Weismann, and Roelleke ${ }^{5}$ introduced a proposal for standardizing mechanical ventilator mode classification. However, by their own admission, there were uncertainties in the proposal. Their white paper referenced work on ventilator mode classification which classified breath sequences and modes of ventilation. The document also addressed the need for nomenclature consensus because of the complexity of the technology involved. However, an actual taxonomy was not proposed in the document, although an ISO subcommittee was formed to develop a standardized vocabulary of mechanical ventilation. A classification system must integrate both historic paradigms, where appropriate, with new ones that allow the taxonomy to be applied to past, present, and future technology. This is a complex and delicate balance that has generated much debate within the ISO subcommittee over the last 3 years. But the goal justifies the effort: Improve the world-wide standard of care for patients on mechanical ventilation by increasing clinicians' understanding, making better use of available technology, and reducing errors.

\section{Statement of Purpose}

The purpose of this study was to determine if stakeholders are familiar enough with published constructs related to modes of mechanical ventilation to form a basis for a consensus by surveying the medical, education, and business communities. 
The aim of the study was to survey a sample of the healthcare community (i.e., including thought leaders* in medicine, education, and business) to establish a baseline level of agreement (hereafter referred to as concordance) with 10 fundamental constructs that could potentially form the basis of a ventilator mode taxonomy. These constructs are derived from previous published works on mode classification in major textbooks and peer reviewed medical journals. The results of this study will inform future efforts to establish an international standard.

\section{Hypotheses}

The specific hypotheses being tested are as follows:

1. Among thought leaders in healthcare, there is sufficient concordance on 10 basic constructs related to mechanical ventilation modes to form the basis for a standardized taxonomy. "Sufficient" in this context will be an average concordance across constructs of $>50 \%$. The value of $50 \%$ was chosen as representing equipoise regarding the constructs.

2. Concordance with the basic constructs will vary among stakeholders according to their professional training and professional activity.

3. The degree of concordance will vary among the set of constructs describing modes of mechanical ventilation.

\footnotetext{
* In this context, "thought leaders" are those individuals who teach concepts of mechanical ventilation, either directly in formal and informal classroom settings or through their published books and articles.
} 


\section{Delimitations of Study}

The study is delimited according to stakeholder categories as follows:

- Health care providers (i.e., physicians, respiratory therapists, and nurses who are experienced with mechanical ventilation in the course of patient care).

- Health care educators (i.e., respiratory care program directors, didactic faculty, clinical instructors).

- Manufacturers (i.e., engineers and product specialists responsible for designing mechanical ventilators and training customers in their use)

The study is also limited to the English language, although most international standards are published in English.

\section{Assumptions of Study}

The major assumptions of this study are as follows:

- Identification of a significant level of concordance among stakeholders will motivate future attempts to achieve a formal consensus at the level of national or international coalitions of health care professionals.

- Identification of patterns of variance in concordance with the constructs according to the focus of the construct or the stakeholder's experience will serve as a basis for targeted education and consensus building.

\section{Limitations of Study}

One of the limitations of the study is the relatively small sample size. There are over 130,000 practicing respiratory therapists in the United States alone and I was able to 
sample only about 400 people internationally from several professions. Another potential limitation was the unequal distribution of responses among professional groups, with therapists dominating and engineers in the minority although this response distribution reflected the sample distribution. Only a small minority of respondents were from business while the vast majority of daily teaching about mechanical ventilation arises from the business sector. On the other hand, almost half of the respondents were from the education sector, and presumably their views determine the mindsets of each new generation of respiratory therapists.

On a practical level, one limitation of this study was that the subject being studied is not well described by the vernacular used. That is, the very words used to conduct the survey were the subject of the survey. In designing the survey, I tried to define the terms as part of the question, yet many if not all respondents had their own beliefs and definitions beforehand. Thus, not only was there bias on my part in creating the survey, there was clearly some level of misunderstanding on the part of the respondents, as indicated by some of the free text comments. This is, however, unavoidable in the absence of a controlled vocabulary for this topic. Indeed, this lack was the very motivation for the study and subsequent action to correct the deficit.

\section{Summary}

The rapid growth of complexity in the design of mechanical ventilators, and particularly modes of ventilation has outpaced the development of a taxonomy capable of supporting educational and patient care efforts. There must be at least a germ of consensus among stakeholders (ie, clinicians, educators, and manufacturers) on key 
constructs if an official taxonomy is to be promulgated. The purpose of this study is to identify a basis for consensus among these stakeholders.

Chapter II will provide a brief historical overview and summary of the relevant literature on the topic.

Chapter III will present the study design, a description of the study sample, and the survey instrument and description of the statistical methods used.

Chapter IV will present the data and results of the statistical analyses.

Chapter V will present the summary and conclusions. Recommendations for future research and action will be presented.

\section{CHAPTER II. INTRODUCTION}

\section{Historical Overview}

Mechanical ventilators were first extensively described in a classic textbook by Mushin et al. ${ }^{6}$ By the $3^{\text {rd }}$ edition in 1980 , the book described performance characteristics of 86 ventilators. However, the vast majority of the ventilators were only available in Europe. The first similar book describing ventilators available in the US was written in 1977. ${ }^{3}$ That book's descriptions were heavily influenced by Mushin et al's book and they focused more on drive mechanisms than modes. Hence, the vocabulary for describing modes was relatively primitive. Three papers appeared in the literature between 1974 and 1991 addressing the need for a ventilator classification scheme. ${ }^{7,8,9}$ In 1991 and 1992 Chatburn published a classification system for mechanical ventilators that was a major break from the Mushin system. ${ }^{10,11,12}$ This system was subsequently adopted by the authors of several textbooks. ${ }^{13,14,15,16,17,18,19}$ There followed a few papers focusing on 
classification of modes of ventilation. ${ }^{20,21,22}$ Eventually these ideas were collated into a book on mechanical ventilation. ${ }^{1}$ The new classification system also appeared in a textbook that is known in academic circles as the "Bible" of mechanical ventilation ${ }^{23}$ as well as in the leading textbook of respiratory care. ${ }^{24}$

\section{Analysis of Published Articles}

One of the first papers on classification of mechanical ventilators was written by Hunger $1961 .{ }^{25}$ The author argued that the then current classification system, based on the inspiratory termination (i.e., cycle) criterion (i.e., volume cycled or pressure cycled) was unsatisfactory because it gave little information about the performance of the machine, and in particular, about its ability to cope automatically with changes in respiratory system mechanics. Instead, this author suggested that the terms "volume preset" and "pressure preset" be used. The distinction is that the focus was shifted from the mechanism that switched from the inspiratory phase to the expiratory phase of a breath to the physics of gas delivery during the inspiratory phase. Mapleson followed with a paper describing the effects of changes in respiratory system mechanics on ventilator performance. ${ }^{26}$ He classified ventilators into two major categories: constantflow generators and constant-pressure generators. This was a slightly more descriptive expression of the idea that Hunter had proposed, but it failed to anticipate the great flexibility of both pressure and volume generators of the future.

The first paper in the respiratory care literature regarding classification of mechanical ventilators appeared in $1974 .{ }^{27}$ That paper was an expanded version of an earlier paper in the British Journal of Anaesthesia published in $1972 .{ }^{28}$ These two papers

represented a break from the dominant classification paradigm established by Mushin, ${ }^{6}$ a 
well know British anesthesiologist who wrote what was considered to be the standard reference textbook of mechanical ventilation until Tobin's book appeared in $1994 .^{29}$ The papers proposed grouping modes based on minute volume, tidal volume, and inspiratory flow. As the basis for classification, the distinction was whether these variables were "stable" or "flexible" in the face of different loads on the ventilator caused by changing respiratory system mechanics. While this system was vaguely similar to that of Hunter, ${ }^{25}$ it was not explicit enough. This system never appeared again in the literature, probably because it was too simplistic to be applicable to the rapidly changing technology in the field of ventilator design.

In 1991, Chatburn published the first paper basing ventilator classification on a mathematical model of the respiratory system. ${ }^{10}$ That model, known as the equation of motion, is a fundamental concept in the field of respiratory physiology and mechanics. The model relates pressure, volume, and flow with a first order, linear differential equation with constant coefficients:

$$
P_{\text {vent }}(t)=E V(t)+R \dot{V}(t)
$$

where $P_{\text {vent }}(t)$ is the pressure generated by the ventilator to inflate the lungs as a function of time, $\mathrm{t}$; $E$ is respiratory system elastance, $V(t)$ is lung volume as a function of time, $R$ is respiratory system resistance, and $\dot{V}(t)$ is inspiratory flow as a function of time. The advantage of basing a ventilator classification system on a model of pulmonary mechanics was that it identified the actual variables (i.e., pressure, volume, and flow) that are monitored and manipulated by the feedback control circuits in ventilators. The model also explicitly describes how these variables change with changing mechanics (i.e., changes in E and R). An elementary explanation of feedback control was also presented 
in the 1991 paper by Chatburn ${ }^{10}$ establishing a precedent for describing modes of ventilation. This, then, was an adequately explicit representation of the idea that $\operatorname{Hunter}^{25}$ had in mind. In 1992, Chatburn published another paper describing how the new classification model could be applied to the task of categorizing mechanical ventilators. ${ }^{11}$ This model-based paradigm has endured to the present.

Also in 1992, Branson and Chatburn extended the model described by Chatburn specifically to modes of ventilation. ${ }^{12}$ This was the first time that the random names created by ventilator manufacturers were explained in terms of a generic classification system. In so doing, it provided the first glimpse of the increasing confusion caused by the proliferation of names used to market new ventilator features.

The next paper on the subject appeared in $2001 .{ }^{20}$ The focus of that paper was on modes of ventilation rather than the ventilators themselves. Of note, this paper was the first to offer a glossary of relevant terms. A paper in 2004 by the same author described the computer control systems that make modes possible. ${ }^{22}$ It was the first paper to name and classify these control algorithms and show a progressive evolution from simpler to more complex and even intelligent systems. The latest paper on the subject of mode classification was published in $2007 .^{30}$ This paper was written in response to the formation of a subcommittee of the ISO for the purpose of creating a "standardized vocabulary" (i.e., a controlled vocabulary) to be used by manufacturers in their ventilator manuals (mentioned above). The paper was used to write a draft ISO vocabulary that has been debated for the past 3 years. Indeed, it was that debate that motivated this study. A controlled vocabulary must have some connection to current practice if it is to be practically implemented. This study, therefore, sought to establish whether the concepts 
published in the published literature of the last 20 years has become part of the current practice to an extent sufficient to justify using them as the basis of a formal taxonomy.

\section{Analysis of Textbooks}

The first widely adopted textbook of mechanical ventilation was written by Mushin et al in the late 1950s. ${ }^{6}$ That book expanded the ideas of Mapelson ${ }^{26}$ by adding "non-constant pressure generators" and "non-constant flow generators". They also added detail to ventilator classification by describing the "phases" of a breath (inspiration, expiration, and the change-over between them) and the mechanisms used by ventilators to accomplish phase changes. However, the book also employed the earlier terms "pressure-cycled" and "volume-cycled" and added "volume-limited" and "pressurelimited”. That system was confusing enough for the times but became completely impractical after the dawn of microprocessor control of mechanical ventilators.

MacPherson ${ }^{3}$ was the first author in the United States to attempt cataloging mechanical ventilators. His system was simply an adaptation of that used in the book by Mushin et al. ${ }^{6}$ Indeed, the focus at that time was in providing detailed descriptions of the drive mechanisms of ventilators rather than creating a system of classification. As there were relatively few devices on the market then, this approach was accepted as the basis for teaching in respiratory care programs throughout the country. Indeed this book was the standard equipment text until it was displaced as the market leader by the book written by Branson, Hess, and Chatburn. ${ }^{31}$ That book based ventilator classification on the earlier papers and book chapter ${ }^{32}$ by Chatburn. Subsequently, McPherson's book changed authors, was renamed Mosby’s Respiratory Care Equipment, and adopted key

aspects of "Chatburn's classification system". ${ }^{33}$ A competing equipment textbook ${ }^{34}$ also 
used “Chatburn's classification system” as the basis for describing ventilators. Both of these textbooks noted that although useful, the "system" had not been adopted universally by practitioners or educators. The "system” has been described in several textbooks on mechanical ventilation. ${ }^{13-19}$

The current "Bible” of mechanical ventilation is Tobin’s Principles and Practice of Mechanical Ventilation. ${ }^{35}$ The second chapter of that book describes Chatburn's classification of mechanical ventilators. ${ }^{23}$ A simplified version of this chapter will appear in the $3^{\text {rd }}$ edition of the Handbook for Respiratory Care (in press). ${ }^{36}$

\section{The Art and Science of Taxonomy}

Taxonomy is the science of classification. ${ }^{37}$ The most common taxonomies have historically been those applied to plants and animals in the form of class, family, genus, species e.t.c. However, the rapid growth of the World Wide Web, and more specifically, the Semantic Web, has created an intense need for organized search strategies that are based on taxonomies and ontgologies. The Semantic Web is an evolving development of the World Wide Web in which the meaning (semantics) of information on the web is defined so that software "agents" can satisfy the search requests of people and machines to use the web content. ${ }^{38}$ Ontologies are advanced forms of taxonomies with a broader scope of information. An ontology might encompass a number of taxonomies, with each taxonomy organizing a subject in a particular way using explicit rules. ${ }^{39}$ Reasons to create taxonomies and ontologies include: ${ }^{40}$

- Sharing common understanding of the structure of information among people or software agents 
- Enabling reuse of domain knowledge

- Making domain assumptions explicit

- Analyzing domain knowledge

Two key steps in creating an ontology are defining classes in the ontology and arranging the classes in a taxonomic (subclass-superclass) hierarchy. The prior literature cited for classification of modes can be viewed as contributing to the definition of classes and a controlled vocabulary for a taxonomy. Controlled vocabulary schemes mandate the use of predefined terms authorized by some official organization. Choosing appropriate authorized terms is difficult because consideration must be given to specificity and logical consistency throughout the domain of application. The prior literature has also laid the foundations for the hierarchical structure of a mode taxonomy. The ISO subcommittee mentioned above may act as the official organization for creating the controlled vocabulary. And, as Noy and McGuinnis point out "It is almost always worth considering what someone else has done and checking if we can refine and extend existing sources for our particular domain and task." 40 Therefore, this study was conceived as a means to support an international effort to create a taxonomy of mechanical ventilation.

\section{Summary}

Beginning in the 1950's textbooks and journal articles have sought to bring some order to the chaos of names associated with modes of mechanical ventilation. Even the earliest authors recognized the need to somehow account for the ventilator's relative ability to respond to changes in the load imposed by the patient's respiratory system caused by changing inspiratory effort or disease processes. The first practical approach to 
this was the introduction of the equation of motion as a mathematical basis for distinguishing pressure control from volume control as major categories of modes. Further refinement of a classification system relied on descriptions of engineering feedback control schemes. Finally, integration of all the fundamental elements of a classification scheme can be achieved with the standard methods for devising taxonomies and ontologies used in other disciplines, notably biology and creation of the Semantic Web.

\section{CHAPTER III. METHODOLOGY}

\section{Study Design}

This study was designed as a survey of stakeholders in a taxonomy of mechanical ventilation. The survey was based on 10 basic constructs (Appendix I) derived from previous published works, as noted above. Briefly, the constructs were as follows

(1) Definition of a breath

(2) Definition of “assisted” breath

(3) Definition of pressure control, PC, and volume control, VC

(4) Definitions of trigger and cycle (i.e., start and stop inspiration)

(5) Machine vs patient triggering and cycling

(6) Definition of spontaneous vs mandatory breaths

(7) Breath sequences: continuous mandatory ventilation, CMV, intermittent mandatory ventilation, IMV, and continuous spontaneous ventilation, CSV 
(8) Ventilatory patterns defined as control variable and breath sequence combinations like VC-CMV or PC-IMV

(9) Adding detail to ventilatory patterns using targeting (i.e., feedback control) schemes.

(10) Using the above constructs to define “mode".

The survey was based on the assumption that astute readers of the previous literature have formed mental concepts similar to these constructs. Thus, such people would be likely to agree with the constructs when they were formulated as specific, concise statements.

\section{Population}

A sample of health care professionals from around the world was surveyed with representation from the medical, education, and business communities. I selected the sample from my personal contacts, and other sources as follows: Educators were identified from published lists of respiratory therapy program directors such as that provided by the Commission on the Accreditation for Respiratory Care (Co-ARC). Clinician thought leaders were selected from published papers on mechanical ventilation in peer reviewed medical journals and from among the authors of textbooks on mechanical ventilation. Authors of published manuscripts were identified using a PubMed search on the key words “mechanical ventilation” encompassing a period of 5 years from 2004 to 2009. Business leaders were selected from among my professional contacts in the ventilator manufacturing industry and included engineers, clinical specialists, and marketing managers. 


\section{Inclusion Criteria}

The following criteria were used in selecting the study population.

- Professional training as a physician, respiratory therapist, nurse, engineer, or other medical professional and familiarity with the topic of mechanical ventilation.

- Recognized thought leader, as determined by contributions to the published literature (clinicians), directing or instructing in a respiratory care program (educators), or designing ventilators or marketing materials (business leaders).

\section{Exclusion Criteria}

No exclusion criteria were imposed after selecting for the inclusion criteria. Emails that were returned as “undeliverable” were of course not included.

\section{Specific Procedures}

Survey Instrument

The survey was first designed and reviewed by my thesis committee. The survey instrument was validated by a pilot study. This pilot study was conducted with a sample of volunteer respondents obtained from respiratory therapist members of the AARC Educational Specialty Section list serve. The survey was returned by 8 respondents. The concordance with individual constructs ranged from 37.5\% to 100\%. The overall concordance was $84 \%$. The results of this pilot study were presented as a poster at the 2009 Respiratory Care Congress in San Antonio, TX, and published in the November issue of Respiratory Care journal (peer reviewed). ${ }^{41}$ The encouraging results of this pilot study prompted the survey of a larger sample of stakeholders. 
The final survey comprised 15 questions, 10 of which related to the constructs framed such that the respondent could respond on a 5 point scale from "strongly agree" to "strongly disagree" (Appendix I). The "correct" answers are indicated in the Appendix in bold. The meaning of correct, in this case, is that the respondent agrees with a statement that supports a construct (or disagrees with a statement that negates a construct) derived from published papers and chapters on mode classification. Questions were designed so that the "correct” answers include both "strongly agree” and "strongly disagree” answers in order to allow calculation of a kappa statistic (Using only "strongly agree" answers would violate the mathematical assumption of the statistic).

One additional question was designed to distinguish whether the primary goal of a taxonomy for mechanical ventilation is to serve clinicians or business. Three more questions were designed to help stratify results according to respondent training and primary professional activity (i.e., patient care, education, or business). This data may prove helpful in designing and disseminating subsequent educational materials.

Participants were recruited through email. Informed consent was implied and incorporated in the introduction to the survey (Appendix I). The survey was administered using the Internet service SurveyMonkey.com. The survey was reviewed by the Youngstown State University IRB and granted exempt status (Appendix II).

Invitations to participate in the survey were emailed internationally to 385 educators, 112 authors of ventilation articles, 160 manufacturers' representatives, and 2,337 other people identified as respiratory care professionals having involvement with mechanical ventilation. A total of 2,994 survey invitations were sent worldwide. 


\section{Outcome Measures}

The survey was worded such that the respondents were asked whether they agreed or disagreed with 10 theoretical constructs. Because acceptance of the underlying construct of a given question could be represented either as “agree” or “disagree”, depending on the wording of the question, the primary outcome measure was defined as average concordance of survey respondents. A secondary outcome was calculation of the kappa statistic to quantify the overall concordance.

\section{Data Analysis}

There are 5 possible responses (ie, an ordinal scale from strongly disagree to strongly agree) for 11 of the survey questions. Responses to the questions were counted as concordant if they supported the underlying construct. For example, question 2 stated that an assisted breath is one for which the ventilator does work on the patient. All the “strongly agree” and "agree” responses to this question were counted as concordant responses while all the "neutral”, “disagree” and "strongly disagree” responses were counted as discordant.

Questions 4, 5, and 8 were worded such that disagreement supported the underlying construct and thus responses of "disagree" and "strongly disagree” were counted as concordant. For example, question 5 was: "Knowing what actions start (trigger) and stop (cycle) inspiration has little clinical significance.” The underlying construct is that trigger and cycle actions do have clinical significance. Therefore, all responses of “disagree” and "strongly disagree” were counted as concordant while responses of “neutral”, “agree”, and “strongly agree” were counted as discordant for this item. Concordance for the set of 10 questions was calculated as the sum of the 
concordant responses divided by the total number of responses, i.e., the percent of responses that supported or agreed with the underlying constructs.

Hypothesis 1: To test the hypothesis that sufficient concordance exists to establish a consensus, the overall concordance percentage was compared to the arbitrary value of $50 \%$ using a Chi Square test.

Hypothesis 2: To test the hypotheses that concordance varies among stakeholders stratified by profession, and professional activity, percent concordances were compared using Chi Square tests.

Hypothesis 3: To test the hypothesis that concordance differs among constructs, percent concordance was compared using a Chi Square test.

For all hypotheses tests, differences associated with $\mathrm{P}$ values $<0.05$ were considered significant. Qualitative ranking of the degree of agreement based on the kappa statistic was done using the system of Landis and $\mathrm{Koch}^{42}$ as described by Feinstein ${ }^{43}$ as shown in Table 1.

Table 1. Qualitative ranking of the degree of agreement based on the kappa statistic.

$\begin{array}{ll}\text { Kappa Value } & \text { Agreement } \\ -1 \text { to } 0 & \text { poor } \\ 0 \text { to } 0.2 & \text { slight } \\ 0.2 \text { to } 0.4 & \text { moderate } \\ 0.6 \text { to } 0.8 & \text { substantial } \\ 0.8 \text { to } 1.0 & \text { almost perfect } \\ 1.0 & \text { perfect }\end{array}$




\section{Summary}

This study was a survey of stakeholders who should have interest in a taxonomy of mechanical ventilation. The survey was formulated from 10 basic constructs derived from previous published works on the subject of mode classification. The data were analyzed to determine if sufficient concordance with the constructs exists to declare a consensus and inform future education and consensus building activities.

\section{CHAPTER IV. RESULTS}

\section{Description of Subjects}

Of the 2,994 surveys emailed to potential respondents, 185 were returned as "undeliverable”. Thus, the sample size for the survey was estimated to be 2, 809 people, although it was probably smaller due to some emails never being delivered or read. I received survey responses from 432 individuals (15.4 \% response rate) between 5/8/09 to 10/9/09. The total response grouped by primary professional training is shown in Table 2 .

Table 2. Survey response grouped by professional training.

\begin{tabular}{lrr}
\multicolumn{1}{r}{ Professional Training } & \multicolumn{1}{c}{ N } & \multicolumn{1}{c}{$\%$} \\
\hline Respiratory therapist & 239 & 55.3 \\
Physician & 153 & 35.4 \\
Any other professional group & 23 & 5.3 \\
Nurse & 11 & 2.5 \\
Engineer & 6 & 1.4 \\
\hline
\end{tabular}


The years of experience for the professional groups are shown in Table 3.

Table 3. Years of professional experience.

\begin{tabular}{lrr}
\multicolumn{1}{c}{ Years of Experience } & Mean & \multicolumn{1}{c}{ SD } \\
\hline Nurse & 26.5 & 10.7 \\
Respiratory therapist & 24.1 & 9.1 \\
Engineer & 21.2 & 8.6 \\
Any other professional group & 21.2 & 11.2 \\
Physician & 17.1 & 7.9 \\
\hline
\end{tabular}

The total response grouped by primary professional activity is shown in Table 4.

Table 4. Survey response grouped by professional activity.

\begin{tabular}{lrr}
\multicolumn{1}{c}{ Professional Activity } & \multicolumn{1}{c}{$N$} & \multicolumn{1}{c}{$\%$} \\
\hline Clinical & 189 & 43.8 \\
Education & 186 & 43.1 \\
Business & 38 & 8.8 \\
Any other professional training & 19 & 4.4 \\
\hline
\end{tabular}

\section{Data Analysis for Hypothesis 1}

The concordance for all responses was calculated as the total number of concordant responses divided by the total number of responses. The overall concordance was $82.4 \%$ which was significantly larger than the postulated $50 \%(\mathrm{P}<0.001$, Table 2$)$. The Chi square $2 \times 2$ contingency table was constructed such that the total number of concordant and discordant responses (3,535 and 757 respectively) were in the "Survey" column and responses expected by chance, ie, 50\%, were in the "Chance” column $(2,155)$ as shown in Table 5. The data support the first hypothesis that sufficient (ie, $>50 \%$ ) concordance exists to establish a consensus. 
Table 5. Results of statistical analysis for hypothesis 1.

\begin{tabular}{|c|c|c|}
\hline & Survey & Chance \\
\hline \multirow[t]{5}{*}{ Row 1} & 3553 & 2155 Counts \\
\hline & 2854 & 2854 Expected Counts \\
\hline & 62.246 & 37.754 Row $\%$ \\
\hline & 82.436 & 50 Column $\%$ \\
\hline & 41.218 & 25 Total $\%$ \\
\hline \multirow[t]{5}{*}{ Row 2} & 757 & 2155 Counts \\
\hline & 1456 & 1456 Expected Counts \\
\hline & 25.996 & 74.004 Row $\%$ \\
\hline & 17.564 & 50 Column \% \\
\hline & 8.782 & 25 Total $\%$ \\
\hline \multicolumn{3}{|c|}{ Power of performed test with alpha $=0.050: 1.000$} \\
\hline \multicolumn{3}{|c|}{$\begin{array}{l}\text { Yates correction for continuity was used in calculating this test } \\
\text { Chi-square }=1012.103 \text { with } 1 \text { degrees of freedom. }(P=<0.001)\end{array}$} \\
\hline
\end{tabular}

The kappa statistic was evaluated with an online calculator ${ }^{44}$ for the $2 \times 2$ matrix shown in Figure 1. The kappa statistic was 0.617 (95\% confidence interval 0.592 to 0.642). This value for kappa corresponds to a quantitative level of “substantial” agreement. $^{43}$

Figure 1. Matrix used to calculate the kappa statistic. $A=$ sum of concordant responses for positively worded survey questions 1-3, 6-7, and 9-10. B = sum of discordant responses for negatively worded survey questions 4-5, and 8. $C=$ sum of discordant responses for questions 1-3, 6-7, and 9-10. $D=$ sum of concordant responses for questions 4-5, and 8. The numbers below the letters represent number of responses.

\begin{tabular}{c|c|c|}
\multicolumn{1}{c}{} & \multicolumn{2}{c}{$\begin{array}{c}\text { Ideal Response } \\
\text { agree }\end{array}$} \\
\cline { 2 - 3 } agree & $\mathrm{A}$ & $\mathrm{d}$ \\
Survagree \\
disagree & 2,430 & 172 \\
\cline { 2 - 3 } & $\mathrm{C}$ & $\mathrm{D}$ \\
585 & 1,123 \\
\cline { 2 - 3 } & &
\end{tabular}




\section{Data Analysis for Hypothesis 2}

When the data were grouped by profession, respiratory therapists showed the highest degree of concordance (84.3\%) and "other profession” showed the lowest (79.1\%) as shown in Figure $2(\mathrm{P}=0.006$, Table 6).

Figure 2. Concordance when data were grouped by profession.

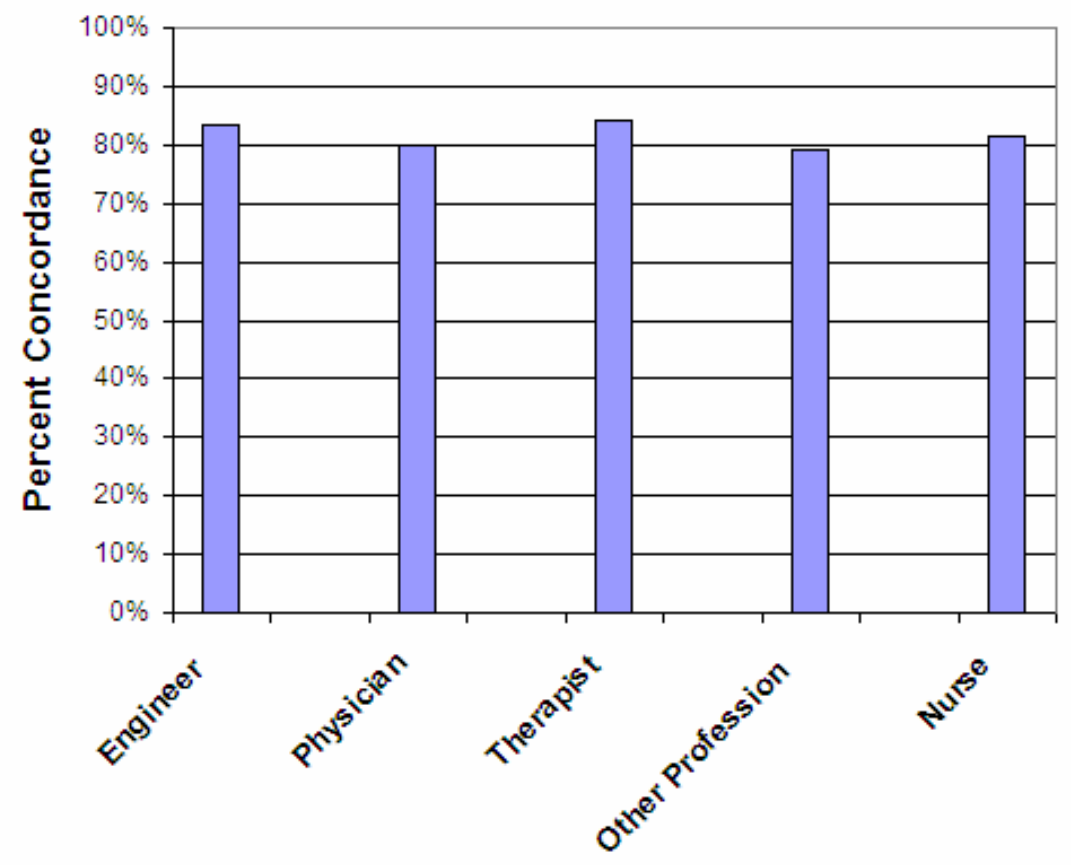

Table 6. Results of statistical analysis for hypothesis 2 related to profession.

\begin{tabular}{rrrrrr}
\multicolumn{7}{c}{ Engineer } & Physician Therapist & Other & \multicolumn{2}{l}{ Nurse } \\
Row 1 & 50.00 & 1221.00 & 2011.00 & 182.00 & 89.00 Counts \\
& 49.42 & 1259.28 & 1965.10 & 189.43 & 89.77 Expected Counts \\
& 1.41 & 34.37 & 56.60 & 5.12 & 2.51 Row \% \\
& 83.33 & 79.86 & 84.28 & 79.13 & 81.65 Column \% \\
& 1.16 & 28.30 & 46.62 & 4.22 & 2.06 Total \% \\
Row 2 & 10.00 & 308.00 & 375.00 & 48.00 & 20.00 Counts \\
& 10.58 & 269.72 & 420.90 & 40.57 & 19.23 Expected Counts \\
& 1.31 & 40.47 & 49.28 & 6.31 & 2.63 Row \% \\
& 16.67 & 20.14 & 15.72 & 20.87 & 18.35 Column \% \\
& 0.23 & 7.14 & 8.69 & 1.11 & 0.46 Total \%
\end{tabular}

Power of performed test with alpha $=0.050: 0.884$

Chi-square $=14.401$ with 4 degrees of freedom. $(P=0.006)$ 
Figure 3 shows a closer look at how the different professional groups answered individual survey questions. All groups tended to show lower concordance on question 3 but particularly so for engineers.

Figure 3. Response to survey questions by different professional groups.

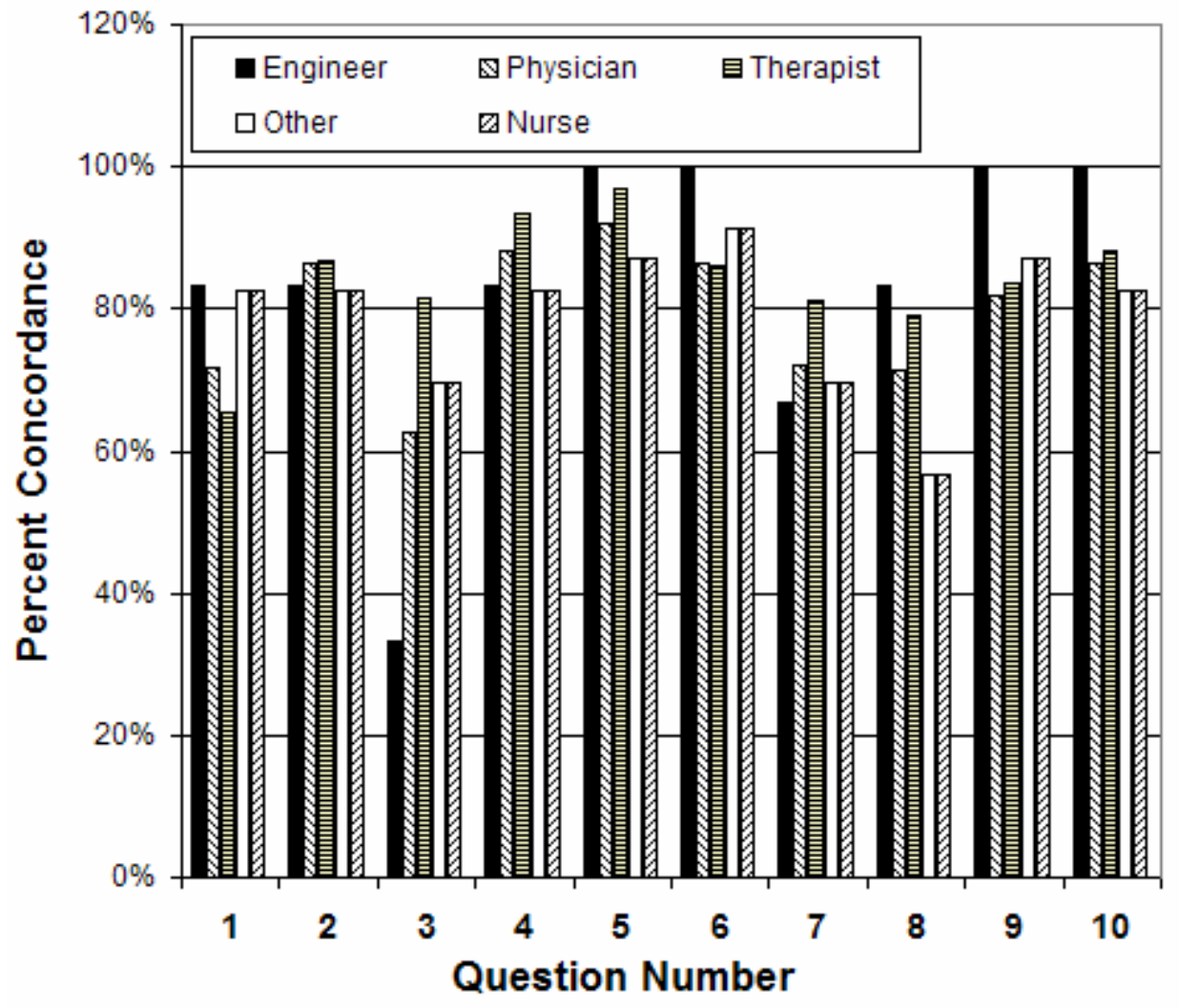


When the data were grouped by professional activity, there was no significant difference in concordance as shown in Figure $4(\mathrm{P}=0.072$, Table 7).

Figure 4. Concordance when data were grouped by professional activity.

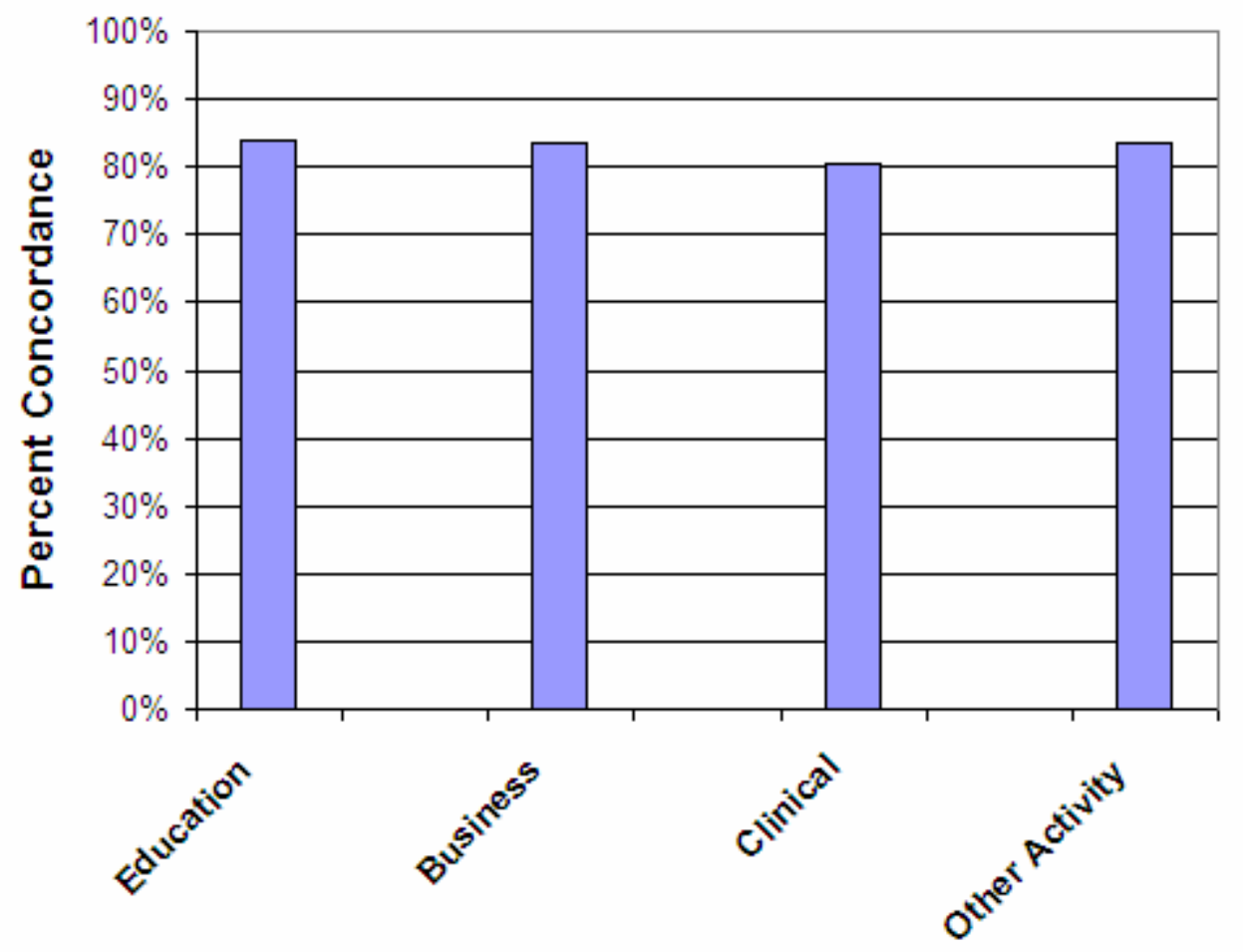

Table 7. Results of statistical analysis for hypothesis 2 related to professional activity.

\begin{tabular}{rrrrc} 
& Education & Business & Clinical & \multicolumn{2}{c}{ Other Activity } \\
Row 1 & 1555 & 317 & 1523 & 158 Counts \\
1528.597 & 312.967 & 1555.776 & 155.66 Expected Counts \\
43.766 & 8.922 & 42.865 & 4.447 Row \% \\
83.782 & 83.421 & 80.625 & 83.598 Column \% \\
36.045 & 7.348 & 35.304 & 3.662 Total \%
\end{tabular}

$\begin{array}{rrrrc}\text { Row 2 } & 301 & 63 & 366 & 31 \text { Counts } \\ & 327.403 & 67.033 & 333.224 & 33.34 \text { Expected Counts } \\ 39.553 & 8.279 & 48.095 & 4.074 \text { Row \% } \\ 16.218 & 16.579 & 19.375 & 16.402 \text { Column \% } \\ & 6.977 & 1.46 & 8.484 & 0.719 \text { Total \% }\end{array}$

Power of performed test with alpha $=0.050: 0.581$

The power of the performed test $(0.581)$ is below the desired power of 0.800 .

You should interpret the negative findings cautiously.

Chi-square $=6.994$ with 3 degrees of freedom. $(P=0.072)$ 
Figure 5 shows a closer look at how the different professional activity groups compared on individual survey questions. Of note, the "other activity" group scored lowest on questions 1 and 2 while the business group scored lowest on question 8.

Figure 5. Response to survey questions grouped by professional activity.

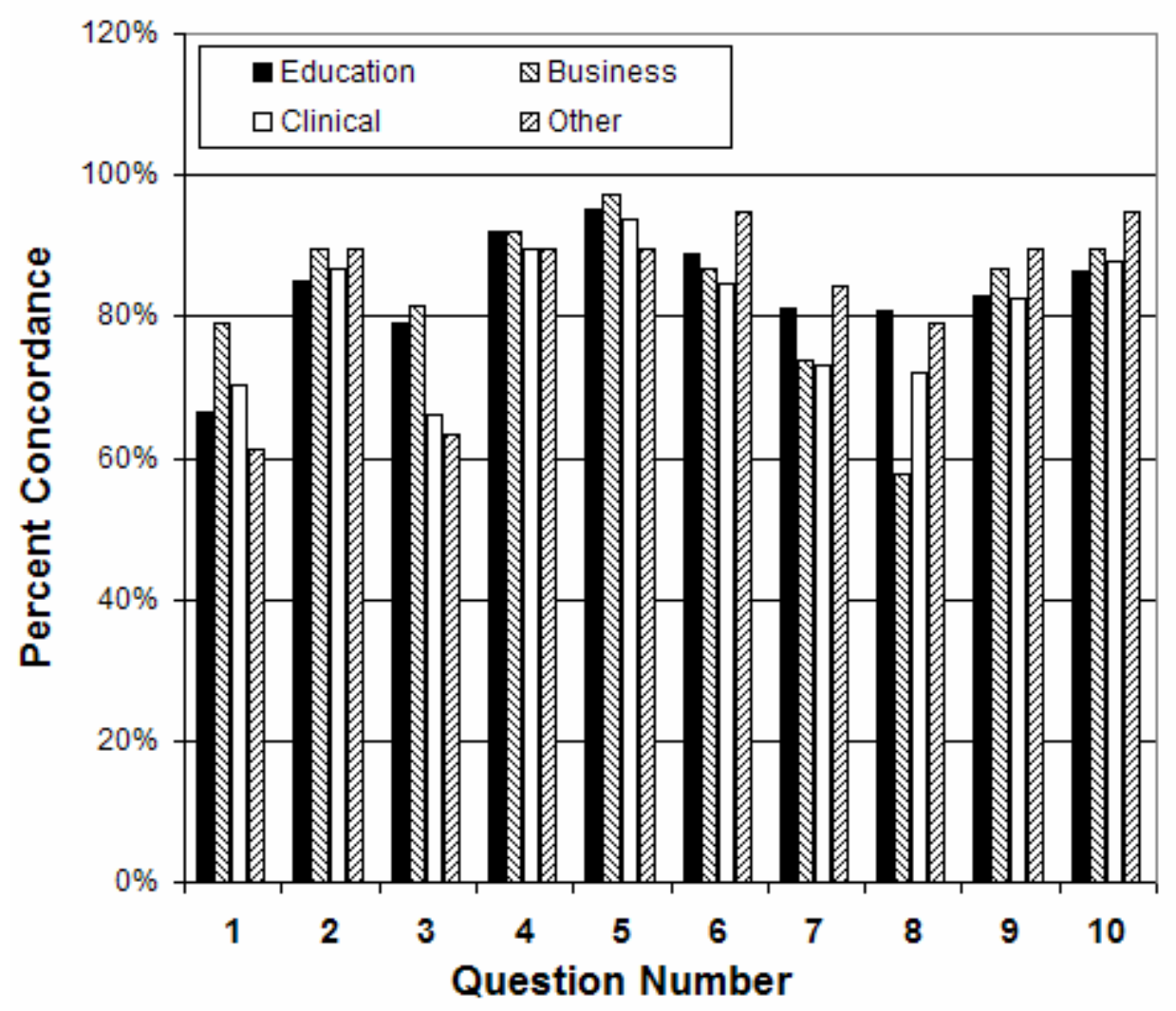




\section{Data Analysis for Hypothesis 3}

Concordance differed significantly among the survey questions as shown in

Figure 6 ( $\mathrm{P}<0.001$, Table 8). Concordance was highest for question 5 (94\%) and lowest for question 1 (69\%).

Figure 6. Comparison of concordance among survey questions.

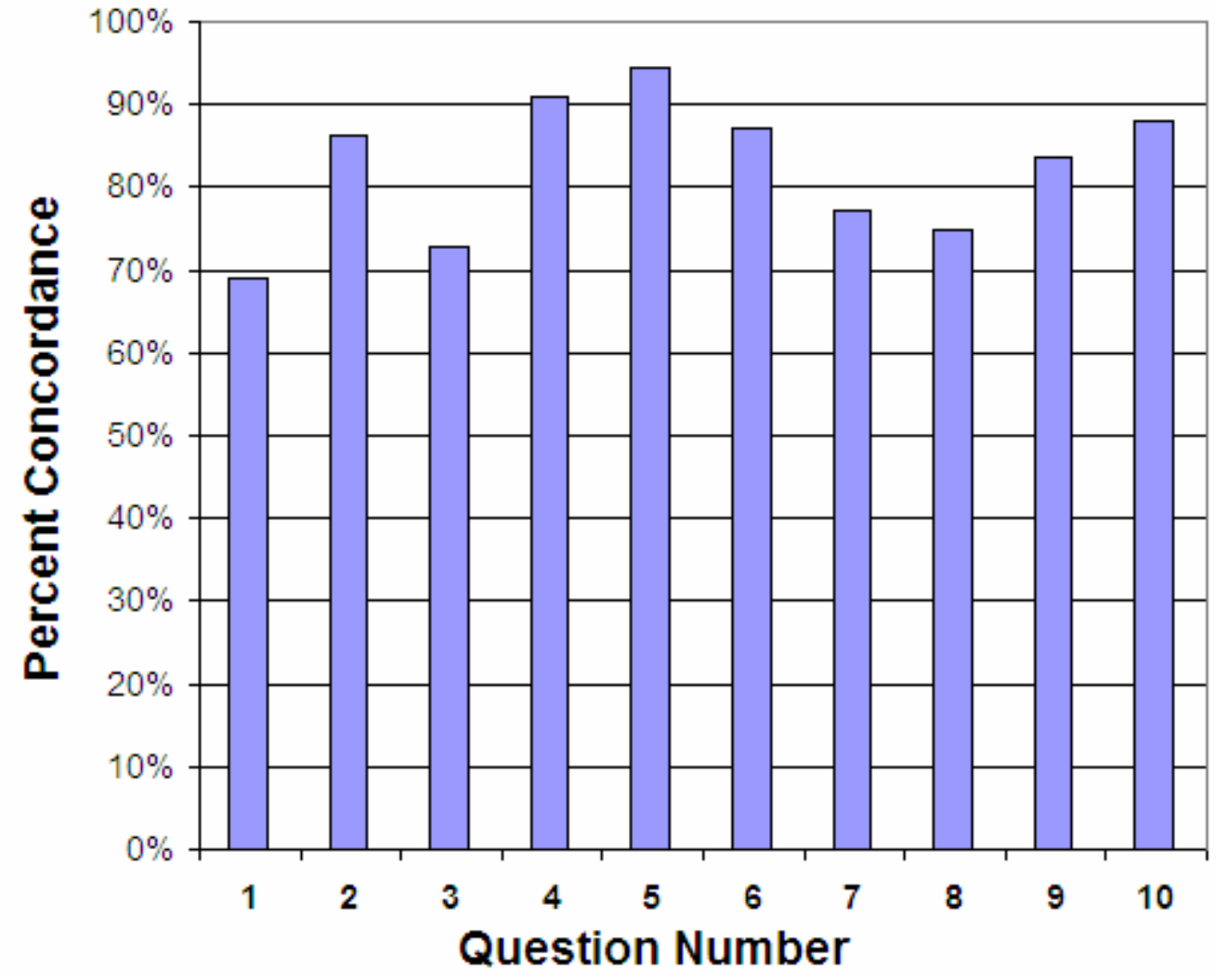


Table 8. Results of statistical analysis for hypothesis 3.

\begin{tabular}{|c|c|c|c|c|c|}
\hline \multicolumn{3}{|c|}{ Concordan Discordant } & \multicolumn{3}{|c|}{ Concordan Discordant } \\
\hline \multirow[t]{5}{*}{ Row 1} & 294 & 132 Counts & Row 6 & 376 & 56 Counts \\
\hline & 351.178 & 74.822 Expected Counts & & 356.124 & 75.876 Expected Counts \\
\hline & 69.014 & 30.986 Row $\%$ & & 87.037 & 12.963 Row $\%$ \\
\hline & 8.275 & 17.437 Column $\%$ & & 10.583 & 7.398 Column $\%$ \\
\hline & 6.821 & 3.063 Total $\%$ & & 8.724 & 1.299 Total \% \\
\hline \multirow[t]{5}{*}{ Row 2} & 373 & 59 Counts & Row 7 & 333 & 98 Counts \\
\hline & 356.124 & 75.876 Expected Counts & & 355.3 & 75.7 Expected Counts \\
\hline & 86.343 & 13.657 Row \% & & 77.262 & 22.738 Row $\%$ \\
\hline & 10.498 & 7.794 Column $\%$ & & 9.372 & 12.946 Column $\%$ \\
\hline & 8.654 & 1.369 Total \% & & 7.726 & 2.274 Total $\%$ \\
\hline \multirow[t]{5}{*}{ Row 3} & 315 & 117 Counts & Row 8 & 323 & 109 Counts \\
\hline & 356.124 & 75.876 Expected Counts & & 356.124 & 75.876 Expected Counts \\
\hline & 72.917 & 27.083 Row $\%$ & & 74.769 & 25.231 Row $\%$ \\
\hline & 8.866 & 15.456 Column $\%$ & & 9.091 & 14.399 Column \% \\
\hline & 7.309 & 2.715 Total $\%$ & & 7.494 & 2.529 Total $\%$ \\
\hline \multirow[t]{5}{*}{ Row 4} & 392 & 39 Counts & Row 9 & 360 & 71 Counts \\
\hline & 355.3 & 75.7 Expected Counts & & 355.3 & 75.7 Expected Counts \\
\hline & 90.951 & 9.049 Row \% & & 83.527 & 16.473 Row $\%$ \\
\hline & 11.033 & 5.152 Column $\%$ & & 10.132 & 9.379 Column \% \\
\hline & 9.095 & 0.905 Total $\%$ & & 8.353 & 1.647 Total \% \\
\hline \multirow[t]{5}{*}{ Row 5} & 408 & 24 Counts & Row 10 & 379 & 52 Counts \\
\hline & 356.124 & 75.876 Expected Counts & & 355.3 & 75.7 Expected Counts \\
\hline & 94.444 & 5.556 Row \% & & 87.935 & 12.065 Row $\%$ \\
\hline & 11.483 & 3.17 Column $\%$ & & 10.667 & 6.869 Column $\%$ \\
\hline & 9.466 & 0.557 Total $\%$ & & 8.794 & 1.206 Total \% \\
\hline
\end{tabular}

Power of performed test with alpha $=0.050: 1.000$

Chi-square $=190.384$ with 9 degrees of freedom. $(P=<0.001)$ 


\section{Analysis of Motivation Question}

Survey question number 11 was aimed at identifying the motivation for creating a taxonomy of ventilator modes. It was phrased as follows: "The primary goal of a ventilator mode taxonomy is to minimize changes required of manufacturers rather than to improve clinician's understanding.” This question was included to determine if any bias might exist either for or against manufacturers' interests given that they are the ones spearheading the official effort to create a standard with the ISO. The overall response was $86 \%$ discordance (i.e., strongly disagree or disagree or neutral). At first thought we might interpret this to be due to the overwhelming majority of responders being outside the business arena. However, the respondents who identified themselves as being in the business group responded with 79\% discordance. This discordance was demonstrated by all other groups as well: clinicians $84 \%$, educators $88 \%$, and other $100 \%$.

\section{Analysis of Comments}

Of the free text comments (Question 15) that expressed a bias, 50 were positive and 43 were negative. Representative comments are shown in Table 9. My favorite positive comment was "Marketing people are going to have a cow over this. They want differentiators, not consensus.” My favorite negative comment was “I am not sure of the intent of this survey; however, the questions are ambiguous at best, confusing at most and too wordy. Looks like someone completing a Master's or Doctoral thesis who has limited experience.” There were 14 comments stating that question 1 was ambiguous or confusing. 
Table 9. Representative free text comments from survey question 15.

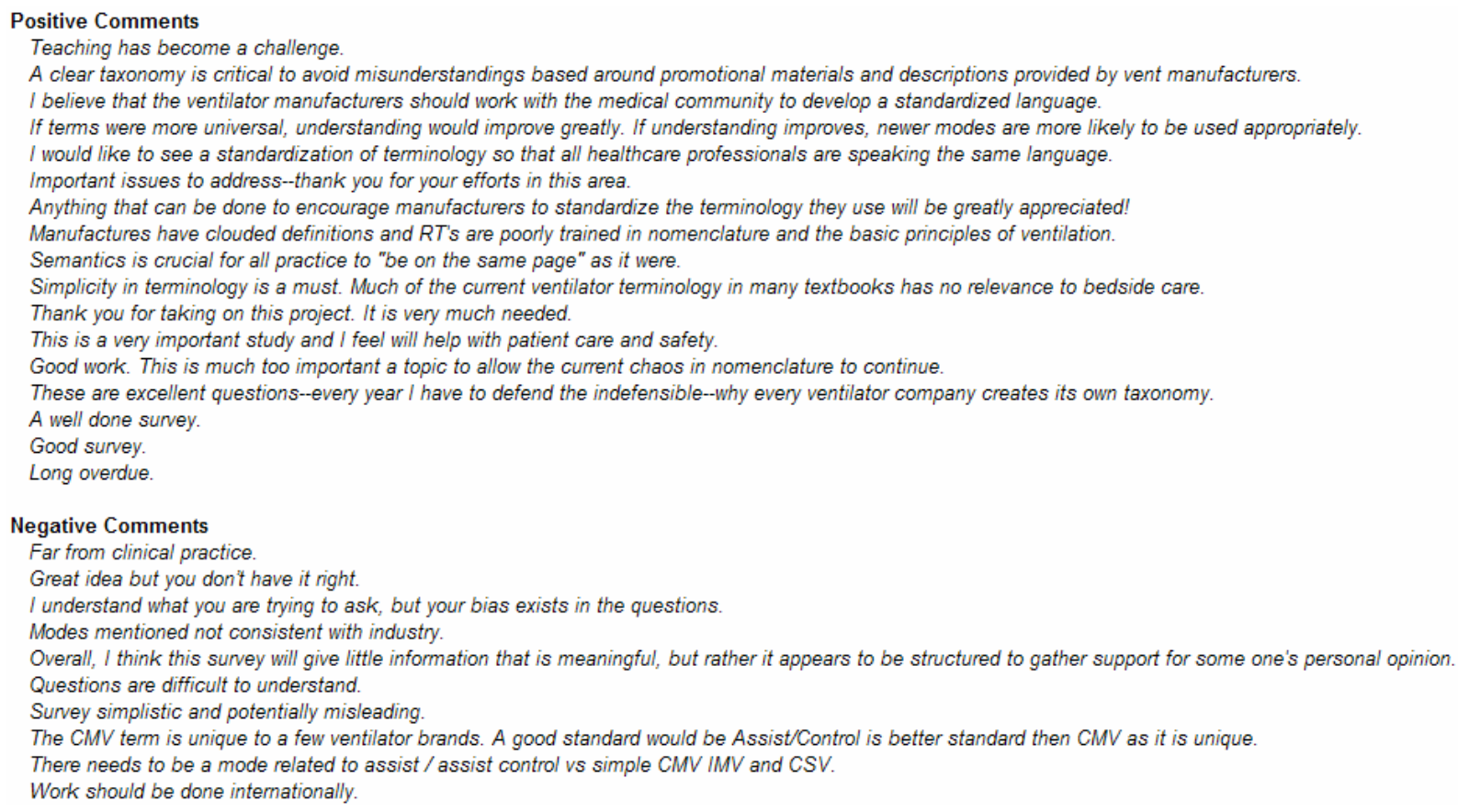

\section{Summary}

The survey was mailed internationally to 2,994 stakeholders in the categories of clinical practice, business and education. The response rate was 15.4\%. Respondents identified themselves as respiratory therapists (55\%), physicians (35\%), nurses (3\%), engineers (1\%) and others (5\%). Average years of experience ranged from 8 to 11 years across the disciplines.

The overall concordance with the 10 constructs of mechanical ventilation was $82 \%$ for the survey. This was significantly larger than the concordance postulated as a level of equipoise (50\%). Based on the associated kappa statistic, the survey response represents a “substantial” level of agreement among all stakeholders.

Respiratory therapists showed a higher concordance (84\%) than the other professions. While this result was statistically significant, it may not be practically important as the maximum difference between therapists and the others was only $5 \%$. 
There was no difference between respondents when grouped by professional activity (education, business, clinical practice, or other).

Also, as hypothesized, the concordance differed among the 10 constructs. The highest concordance (94\%) was for the construct "knowing whether the machine or the patient triggers and cycles inspiration has clinical significance”. The lowest (69\%) was for the construct defining a breath.

In summary, the data from this survey supported all three study hypotheses. 


\section{CHAPTER V. SUMMARY, CONCLUSIONS AND RECOMMENDTIONS}

\section{Summary}

Over the last 30 years, there has been a rapid evolution of the technologic capabilities of mechanical ventilators. These capabilities have motivated the creation of dozens of names to describe modes of ventilation. This proliferation of names has become counterproductive, making education of end users very difficult and potentially affecting the quality of patient care. Recognizing this dilemma, the International Standards Organization has attempted to create a controlled vocabulary of mechanical ventilation to standardize mode descriptions among manufacturers. That effort has led to the appreciation of the larger need to create a taxonomy and even an ontololgy of mechanical ventilation to support future developments in the Semantic Web. This study was conceived to support such endeavors. Specifically, this study sought to determine whether prior publications describing mode terminology and classification were sufficiently disseminated to suggest that an informal consensus currently exists, at least in principle. That consensus was hypothesized to exist among stakeholders in the international respiratory care community including physicians, nurses, engineers and manufacturers’ representatives working in clinical, educational and business environments.

This study generated survey results that indicated a significant level of concordance with 10 basic constructs of mechanical ventilation among stakeholders. Not surprisingly, the level of concordance was highest among respiratory therapists, presumably because they are more familiar with the prior art as it was published in 
journals and textbooks aimed at their profession. Of note was the fact that engineers had the lowest level of agreement with the construct that ventilatory assistance can be achieved “...by only 2 means, control of the inspiratory volume/flow waveform or control of the inspiratory pressure waveform...”. Possible explanations for this result include the fact that they were not aware of the construct because it appeared almost exclusively in clinically oriented journals (as opposed to engineering journals) and because engineers typically recoil at the idea of there being "only" a set number of ways to control a system. Hence, the engineers, as well as many others who responded, may not have appreciated the larger context of the survey questions and tended to interpret them within their own narrow perspective.

The fact that there was no difference among responses when grouped according to professional activity is, perhaps, not surprising. Biases are held by people, not abstract professions. In addition, each professional activity has a mixture of professionals, so any potential differences would tend to be canceled out.

The finding that concordance varied among constructs invites discussion. The least concordant construct was represented by question 1: “A breath is defined as an inspiration paired with an expiration, where the two are matched by size or timing, thus allowing small fast breaths on top of large slow breaths during mechanical ventilation.” The comments indicated that the low concordance with this construct was due, in part, to the perceived complexity/ambiguity of the question. Part of the problem is the compound nature of the construct. But simply postulating that a breath is an inspiration paired with an expiration would have been trivial. The issue of matching of size is relevant in the context of some modes that first impose a large machine initiated inspiration, then allow 
the patient to breathe relatively smaller breaths for a short period, followed by a large machine initiated expiration. There is also the alternative possibility that the ventilator imposes small, rapid breaths upon slower, larger, patient initiated breaths. Clearly, there was no way to explain the full context of the question, yet it had to be asked. Confusion resulted because respondents were not familiar with thinking about the larger context. Nevertheless, if repeated, this question would have to be better worded.

The question with the second lowest concordance was number 2: “A ventilator can assist a breath by only two means; control of the inspiratory volume/flow waveform (ie, volume control) or control of the inspiratory pressure waveform (ie, pressure control)." The lower concordance for this construct may be a direct result of the confusion in the industry about the word "assist". Manufacturers have promulgated the notion that any patient initiated breath is an "assisted" breath. On the contrary, physiologists and physicists tell us that the word assist has nothing to do with what the patient does but rather relies on whether or not the ventilator performs work on the respiratory system. This misunderstanding is tied to a much larger issue affecting the formation of a taxonomy: There is a fundamental disagreement among stakeholders who view the ventilator in terms of how it is used clinically (i.e., from the patient's point of view) and those who view what it does mechanically (i.e., from the ventilator's point of view). For example, the term “Assist/Control” has been very popular for decades to describe a mode wherein either the patient triggers the breath (assist) or the ventilator triggers the breath (control). Yet this is fundamentally a patient-centric view because those who use term are only interested in whether the ventilator responds to the patient's inspiratory effort or whether the breath is imposed on the patient. From the point of view 
of creating a taxonomy, the term Assist/Control is less than useless because it elevates a very low level system feature (the trigger variable) to the most important hierarchical position. Indeed, the terms assist and control as used in this fashion relate to no other constructs in a hierarchical way and are in fact names rather than tags (i.e., a taxonomic attribute groupings). Thus, we may conclude that the low concordance with construct number 2 indicates where more education needs to be directed. In fact, we could argue that this particular construct indicates the key issue: getting people to stop thinking in terms of names promulgated by manufacturers and start thinking about general terms of classification (when appropriate of course, as in educational programs and operator's manuals).

The construct with the next lowest concordance was associated with question number 8: "Being able to identify any mode as one of these 5 basic ventilatory patterns has little practical value: 1. VC-CMV; 2. VC-IMV; 3. PC-CMV; 4. PC-IMV; 5. PC-CSV $\mathrm{VC}=$ volume control, $\mathrm{PC}=$ pressure control.” In order to agree with this construct, the respondent would have to be aware of the expanded definitions of the terms CMV, IMV and CSV. Despite the fact that question 7 (the next higher concordance level) defined these terms, most people probably have a more restricted understanding of them and associate them with specific modes on specific ventilators rather than viewing them as more generic categories of mode characteristics. Again, this bias was expected and indeed, the fact that the majority of responses were concordant is encouraging. 


\section{Conclusions}

In conclusion, the results of this survey indicate that the respondents were either familiar with or amenable to the previously published literature that the survey constructs represented. Furthermore, the degree of familiarity and concordance with these constructs may represent a sufficient basis for attempting to formalize a taxonomy of mechanical ventilation and developing educational materials targeted for key stakeholders.

\section{Recommendations}

The conclusions from this study suggest that the next step would be to publish a paper describing each of the 10 constructs in detail, with the proper context explained, such that they could actually be used together as a logical, consistent system for classifying modes of ventilation. A draft of such a paper has already been created that starts with the definition of a breath and concludes with a complete taxonomy in the form of a class, family, genus, and species approach to classifying all past, current, and hopefully, all future modes of mechanical ventilation. That paper, bolstered by the results of this study, should provide the tools to allow any manufacturer to describe a ventilator's performance concisely or any educator to explain it to students. In the end, that which is useful survives and that which is not becomes extinct. Only time will tell. 


\section{REFERENCES}

1 Chatburn RL. Fundamentals of mechanical ventilation. Cleveland Heights: Mandu Press Ltd, 2003.

2 Chatburn RL, Volsko TA. Documentation issues for mechanical ventilation using pressure control modes. Respir Care 2010 (in press).

3 McPherson SP. Respiratory therapy equipment. Saint Louis: The C.V. Mosby Company, 1977.

4 Cairo JM, Pilbeam SP. Mosby's respiratory care equipment. $7^{\text {th }}$ edition. St. Louis: Mosby, 2004.

5 Beier M, Weismann D, Roelleke TH. Classification of ventilation modes. White paper for discussion at the ISO TC121/SC3 meeting, Helsinki, June 5-9, 2006.

6 Mushin WW, Rendel-Baker L, Thompson PW, Mapelson WW. Automatic ventilation of the lungs. Oxford: Blackwell Scientific Publications, 1959.

7 Baker AB, Murray-Wilson A. Towards a better classification of lung ventilators. Anaesth Intensive Care. 1974 May;2(2):151-157.

8 Manczuk MS. The classification and clinical application of mechanical ventilators. AANA J. 1976 Oct;44(5):501-507.

9 Smallwood RW. Ventilators--reported classifications and their usefulness. Anaesth Intensive Care. 1986 Aug;14(3):251-257.

10 Chatburn RL. A new system for understanding mechanical ventilators. Respir Care. 1991 Oct;36(10):1123-1155.

11 Chatburn RL. Classification of mechanical ventilators. Respir Care 1992;37:10091025.

12 Branson RD, Chatburn RL. Technical description and classification of modes of ventilator operation. Respir Care 1992;37:1026-1055.

13 Branson R, Chatburn RL, Hess D. Respiratory care equipment. 2nd edition. Philadelphia: J. B. Lippincott, 1998.

14 Barnes TA, Chatburn RL. Mechanical ventilation. In: Barnes TA, editor.Core textbook of Respiratory Care Practice. Chicago: Mosby - Year Book 1994.

15 Carlo WA, Ambalavanan N, Chatburn RL. Classification of mechanical ventilation devices. In: Sinha SK. Donn SM. Manual of Neonatal Respiratory Care. Armok NY: Futura Publishing Company, Inc. 2000.

16 Chatburn RL, Scanlan CL. Ventilator modes and functions. In: Scanlan C. Egan’s Fundamentals of Respiratory Care. 7th ed. Chicago: Mosby - Year Book 1999. 
17 Chatburn RL. Classification of mechanical ventilators. In: Tobin MJ, ed. Principles and practice of mechanical ventilation. New York: McGraw-Hill, 1994.

Chatburn RL. Engineering principles of ventilatory support devices. In: Scanlan C. Egan's Fundamentals of Respiratory Care. 6th ed. Chicago: Mosby - Year Book 1995.

19 Chatburn RL, Branson RD. Classification of mechanical ventilators. In: MacIntyre NR, Branson RD. Mechanical Ventilation. Philadelphia: W. B. Saunders Co., 2001.

20 Chatburn RL, Primiano FPJr. A new system for understanding modes of mechanical ventilation. Respir Care 2001;46(6):604-621.

21 Chatburn RL. Engineering principles applied to mechanical ventilation. IEEE Engineering in Biology and Medicine proceedings, 2003. Available at http://ieeexplore.ieee.org/Xplore/guesthome.jsp (last accessed 10/24/2006).

22 Chatburn RL. Computer control of mechanical ventilation. Respir Care 2004;49(5):507-515.

23 Chatburn RL. Classification of mechanical ventilators, $2^{\text {nd }}$ edition. In: Tobin MJ, ed. Principles and practice of mechanical ventilation. New York: McGraw-Hill, 2006.

24 Chatburn RL, Volsko TA. Mechanical Ventilators. In: Egan’s Fundamentals of Respiratory Care. $9^{\text {th }}$ Edition. St. Louis: Mosby Elsevier, 2009:965-999. Hunter AR. The classification of respirators. Anaesthesia 1961;16(2):231-234.

Mapleson WW. The effect of changes of lung characteristics on the functioning of automatic ventilators. Anaesthesia 1962;17(3):300-314.

27 Grogono AW, Sinopoli LM. A new classification system for intermittent positive pressure ventilatrs. Respir Care 1974;19(3):199-202.

28 Grogono AW. The classification of intermittent positive pressure ventilators. Br J Anaesth 1972;44(4):405-407.

29 Tobin MJ, ed. Principles and practice of mechanical ventilation. New York: McGraw-Hill, 1994.

30 Chatburn RL. Classification of ventilator modes: Update and proposal for implementation. Respir Care 2007;52(3):301-323.

31 Branson R, Chatburn RL, Hess D. Respiratory care equipment. Philadelphia: J. B. Lippincott (1995).

32 Chatburn RL. Assisted ventilation. In: Blumer JL. Pediatric intensive care. St. Louis: C. V. Mosby, 1990.

33 Cairo JM, Pilbeam SP. Mosby’s Respiratory Care Equipment. $8^{\text {th }}$ edition. St. Louis: Mosby Elsevier, 2010.

34 White GC. Equipment theory for respiratory care. $4^{\text {th }}$ edition. Clifton Park: Thomson Delmar Learning, 2005. 
35 Tobin MJ, ed. Principles and practice of mechanical ventilation. $2^{\text {nd }}$ edition. New York: McGraw-Hill, 2006.

36 Chatburn RL, Mireles-Cabodevila. Handbook of respiratory care. $3^{\text {rd }}$ edition. Boston: Jones and Bartlett Publishers, (in press).

37 http://en.wikipedia.org/wiki/Taxonomy (accessed 3/27/2010).

38 Berners-Lee T, Hendler J. The semantic web. Scientific American, May, 2001. http://citeseerx.ist.psu.edu/viewdoc/download?doi=10.1.1.115.9584\&rep=rep1\&type $=$ pdf (accessed 3/27/2010).

39 http://www.ideaeng.com/tabId/98/itemId/199/Whats-the-difference-betweenTaxonomies-and-Ontol.aspx (accessed 3/27/2010).

40 Noy NF, McGuinness DL. Ontology Development 101: A Guide to Creating Your First Ontology. Stanford University http://protege.stanford.edu/publications/ontology_development/ontology101-noymcguinness.html (accessed 3/27/2010).

41 Chatburn RL. Determining the basis for a taxonomy of mechanical ventilation. Respir Care. 2009;54(11):1555.

42 Landis JR, Koch GG. The measurement of observer agreement for categorical data. Biometrics 1977;33:159-174.

43 Feinstein AR. Principles of medical statistics. Boca Raton: Chapman \& Hall/CRC. 2002:415-417.

44 http://faculty.vassar.edu/lowry/kappa.html (accessed 3/26/2010). 


\section{APPENDIX I: SURVEY INSTRUMENT}

Thank you for participating in this survey. It is designed to determine if a consensus exists regarding a proposed taxonomy (classification system) based on current understanding regarding modes of mechanical ventilation.

You will be asked whether you agree with some basic statements related to the fundamental concepts that might comprise the taxonomy. Your participation should take approximately 5 minutes.

There are no risks to you. The assessment is anonymous, and all information will be handled in a strictly confidential manner, so that no one will be able to identify you when the results are recorded and/or reported.

Your participation in this study is voluntary and you may withdraw without negative consequences. Please feel free to contact Dr. Salvatore Sanders, Faculty Advisor, at 330.941.7157 or Dr. Edward Orona, Director of the Department of Office of Grants and Sponsored Programs at 330-941-2377 if you have any questions about the study.

We would greatly appreciate your participation. By completing in this survey, you are agreeing to participate in this study described above and confirm that you are 18 years of age or older.

\section{SURVEY QUESTIONS}

Answers that agree with the construct upon which the question is based are shown in bold. Note: bold answers are shown here only for reference and will not be shown on the actual survey.

1. A "breath" is defined as an inspiration paired with an expiration, where the two are matched by size or timing, thus allowing small fast breaths to be superimposed on large slow breaths during mechanical ventilation.

- Strongly Agree

- Agree

- Neutral

- Disagree

- Strongly Disagree 
2. An "assisted" breath is one for which the ventilator performs some work on the patient, as evidenced by airway pressure rising above baseline on inspiration or falling below baseline on expiration.

- Strongly Agree

- Agree

- Neutral

- Disagree

- Strongly Disagree

3. A ventilator can assist a breath by only two means; control of the inspiratory volume/flow waveform (ie, volume control) or control of the inspiratory pressure waveform (ie, pressure control).

- Strongly Agree

- Agree

- Neutral

- Disagree

- Strongly Disagree

4. Knowing what actions start (trigger) and stop (cycle) inspiration has little clinical significance.

- Strongly Agree

- Agree

- Neutral

- Disagree

- Strongly Disagree

5. Knowing whether the machine or the patient triggers and cycles a given inspiration has little clinical significance.

- Strongly Agree

- Agree

- Neutral

- Disagree

- Strongly Disagree

6. A spontaneous breath may be defined as one for which the patient both triggers and cycles inspiration (note that this is a general definition and does not require that the patient be connected to a ventilator). A mandatory breath may be defined as one for which inspiration is triggered and/or cycled by the machine.

- Strongly Agree

- Agree

- Neutral

- Disagree

- Strongly Disagree 
7. There are 3 basic breath sequences:

- Continuous mandatory ventilation (CMV; all breaths are mandatory),

- Intermittent mandatory ventilation (IMV; spontaneous breaths may occur between mandatory breaths), and

- Continuous spontaneous ventilation (CSV; all breaths are spontaneous).

- Strongly Agree

- Agree

- Neutral

- Disagree

- Strongly Disagree

8. Being able to identify any mode as one of these 5 basic ventilatory patterns has little practical utility:

1. VC-CMV

2. VC-IMV

3. PC-CMV

4. PC-IMV

5. PC-CSV

$\mathrm{VC}=$ volume control, $\mathrm{PC}=$ pressure control.

- Strongly Agree

- Agree

- Neutral

- Disagree

- Strongly Disagree

9. There is practical utility in differentiating modes by describing the feedback control (targeting) schemes used to determine pressure, volume, and flow delivery both within and between breaths. This would allow, for example, a standardized description of the difference between conventional PC-CMV and "Pressure Regulated Volume Control".

- Strongly Agree

- Agree

- Neutral

- Disagree

- Strongly Disagree

10. A mode of ventilation may be defined as a unique combination of control variable, ventilatory pattern and targeting scheme(s).

- Strongly Agree

- Agree

- Neutral

- Disagree

- Strongly Disagree 
11. The primary goal of a ventilator mode taxonomy (classification system) is to minimize changes required of manufacturers rather than to maximize clinician's understanding.

- Strongly Agree

- Agree

- Neutral

- Disagree

- Strongly Disagree

12. My primary professional training is:

- Physician

- Respiratory Therapist

- Nurse

- Engineer

- Other

13. My primary professional activity is?

- Business

- Patient Care

- Education

- Other

14. How many years of experience do you have related to your primary professional activity?

15. If you have any comments related to the concepts presented in this survey, please take a moment to share them with me: 


\section{APPENDIX II: IRB APPROVAL}

\section{Youngstown \\ STARE UNIVERSIYY

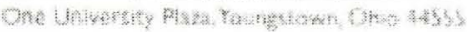

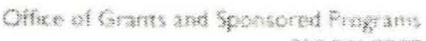

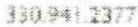 \\ Fi* 330 9.4 3205}

138xา $16 \times 2000$

Dr, Salvatore Sanders, Principal Investigator

Mr. Rohert Chatburn, Cos-investgator

Departuenta of Heall Prolessions

UNIVERSTY

RE: HSRC Protocol Number: 169-2009

Tille: Deternining the Basis for a Taxomony of Mechanical Ventilatwen

Dear Dr Sanders and Mr. Chatban:

The Humar Sabjects Research Conmitte has revewed the abovenemioned prowool and determined that it is exempt from full comminte review based on a DHHS

Catcgory 2 exemption.

Any changes in your research activity should be promply reported to the Human Subjects kesearch Committee and may not he initiated withou HSRC approval except where necessary to eliminate hazard to human stabjects. Any unantic ipated problens involving risks io subjects should also be promptly reported to the Human Subjects Research Commuttee.

The HSRC would like to extend its hest wishes to you in the contuct of this study

Sincerely.

Petier J. Kasvinsky

Dean. School of Graduate Studics

Rescarch Complance Officer

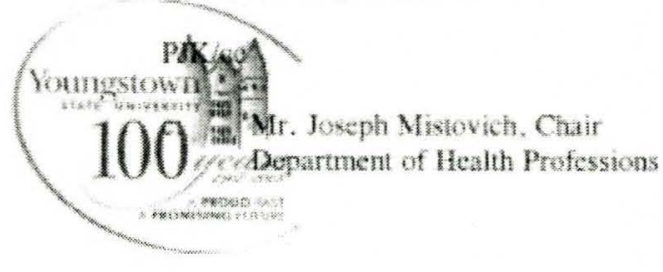

www.ysu.edu $(-3)$ 